\title{
Sampling Apple Trees to Accurately Estimate Mean Fruit Weight and Fruit Size Distribution
}

\author{
Richard P. Marini ${ }^{1}$ \\ Department of Plant Science, The Pennsylvania State University, 203 Tyson \\ Building, University Park, PA 16802
}

James R. Schupp

Fruit Research and Extension Center, The Pennsylvania State University, 290 University Drive, Biglerville, PA 17307

\section{Tara Auxt Baugher}

The Pennsylvania State University, Cooperative Extension in Adams County, 670 Old Harrisburg Road, Gettysburg, PA 17325

\section{Robert Crassweller \\ Department of Plant Science, The Pennsylvania State University, 7 Tyson Building, University Park, PA 16802}

Additional index words. Malus $\times$ domestica Borkh, predicted fruit size distribution, predicted fruit size

\begin{abstract}
Canopies of 'Gala' and 'Fuji' trees, trained to the vertical axis, were divided into eight vertical sections, each representing $12.5 \%$ of the tree canopy. The diameter of all 'Gala' fruit and fruit weight for all ' $F u j i$ ' fruit were recorded for each canopy section. Fruit size from most canopy sections was normally distributed and distributions were similar for most sections. Therefore, fruit size distribution for a tree can be estimated by harvesting fruit from two sections of a tree, representing $25 \%$ of the canopy. For small trees in intensive plantings, with canopy diameters less than $2.0 \mathrm{~m}$, average fruit diameter or fruit weight estimated from all fruit collected from $25 \%$ of the canopy may provide estimates within $7 \%$ of the true value.
\end{abstract}

Early-season estimates of fruit size distributions would be beneficial for apple growers and packers to develop intelligent marketing plans for the upcoming harvest season. Although apple fruit weight data usually fit a normal distribution (Clarke, 1990; Visser and Pieterse, 1977; Webb et al., 1980; Zhang et al., 1995), methods for sampling trees to obtain accurate estimates of fruit size distribution have not been published.

Apple researchers often use average fruit size as an indicator of how various treatments affect fruit size. Obtaining the true average fruit weight involves counting and weighing all the fruit harvested from a tree and dividing the total weight by the number of fruit. However, harvesting entire trees or plots may be expensive and time-consuming and

Received for publication 11 Feb. 2019. Accepted for publication 22 Mar. 2019.

This research was supported by the U.S. Department of Agriculture National Institute of Food and Agriculture and Regional Research Appropriations under Project 4625 and the Pennsylvania Department of Agriculture Research Program. We acknowledge the valuable contributions of Edwin Winzeler (Penn State Fruit Research and Extension Center) and Dan and Mark Boyer (grower cooperators).

${ }^{1}$ Corresponding author. E-mail: rpm12@psu.edu. often requires considerable labor. Some researchers have reported true mean fruit weight calculated from the entire population of fruits on a tree (Dozier et al., 1980; Hampson et al., 1997; McClure and Cline, 2015; Stefanelli et al., 2009), whereas others have graded the fruit into various size categories to obtain the true fruit size distribution (Barden and Marini, 1998; Marini et al., 1993; Schupp et al., 2017). Due to limited time and funds, many researchers use various sampling schemes to harvest a portion of the fruit on experimental trees to estimate average fruit size for a tree and assume the fruit characteristics of the sample population adequately represent the characteristics of the entire population of fruit on the tree (Dozier et al., 1980; Fallahi et al., 2011; Greene, 1986; Miller, 1982). Marini (2001) estimated mean fruit weight using two sampling schemes. Estimates obtained from a 20 -fruit sample per tree differed from the true mean by about $13 \%$, and estimates obtained by weighing all fruit on three limbs per tree differed from the true mean by $11 \%$ to $19 \%$. The impact of many treatments on average fruit size is less than $15 \%$ and conclusions concerning the impact of those treatments on fruit size may be erroneous due to inappropriate fruit sampling schemes. The objective of this study was to identify a sampling scheme that will provide accurate estimates of average fruit weight as well as fruit size distributions for individual trees.

\section{Materials and Methods}

Trees in two orchards were used for this study in 2016. Nine 'Buckeye Gala' trees, on M.9 NAKBT337 rootstock, planted in 2009, and trained to a vertical axis, were selected in a commercial orchard in Fishertown, PA (lat. $40^{\circ} 7^{\prime} 40^{\prime \prime} \mathrm{N}$, long. 78 $\left.31^{\prime} 37^{\prime \prime} \mathrm{W}\right)$. Trees were planted $0.91 \times 3.7 \mathrm{~m}$, were about $2.4 \mathrm{~m}$ tall and $1.8 \mathrm{~m}$ in diameter at the base of the canopy, average trunk cross-sectional area was $2.2 \mathrm{~cm}^{2}$, and rows were oriented in a southeast-northwest direction. Thirteen 'Aztec Fuji' trees on M.9 NAKBT337 rootstocks, planted in 2008, were selected at Penn State's Fruit Research and Extension Center in Biglerville, PA (lat. 39 $56^{\prime} 22^{\prime \prime} \mathrm{N}$, long. $\left.77^{\circ} 15^{\prime} 25^{\prime \prime} \mathrm{W}\right)$. Trees were planted $0.91 \times 3.7 \mathrm{~m}$, were $3.5 \mathrm{~m}$ tall and $1.8 \mathrm{~m}$ in diameter at the base of the canopy, average trunk cross-sectional area was $3.8 \mathrm{~cm}^{2}$, and rows were oriented northeast-southwest. At Biglerville, 'Fuji' trees were thinned with $100 \mathrm{mg} \cdot \mathrm{L}^{-1}$ 6-benyladenine (MaxCel, Valent U.S.A., Walnut Creek, CA) plus $600 \mathrm{mg} \cdot \mathrm{L}^{-1}$ carbaryl (Carbaryl 4L; Loveland Products, Inc., Greeley, CO) when average fruit diameter was about $12 \mathrm{~mm}$. Sprays were applied with an air-blast sprayer calibrated to apply $935 \mathrm{~L} \cdot \mathrm{ha}^{-1}$, and follow-up hand thinning was not needed. At Fishertown, 'Gala' trees were thinned with $600 \mathrm{mg} \cdot \mathrm{L}^{-1}$ carbaryl (Carbaryl 4L; Loveland Products, Inc.) plus $2.5 \mathrm{ml} \cdot \mathrm{L}^{-1}$ spray oil delivered with an air-blast sprayer calibrated to apply $935 \mathrm{~L} \cdot \mathrm{ha}^{-1}$, and follow-up hand thinning was required to retain one fruit per spur about every $15 \mathrm{~cm}$ along the limb.

At harvest time, each tree was divided into eight equal-size vertical slices on a compass direction by hanging strips of flagging vertically on the periphery of each canopy. The eight canopy sections will be referred to as $\mathrm{N}=$ north, $\mathrm{NE}=$ northeast, $\mathrm{E}=$ east, $\mathrm{SE}=$ southeast, $\mathrm{S}=$ south, $\mathrm{SW}=$ southwest, $\mathrm{W}=$ west, and $\mathrm{NW}=$ northwest. The diameter of all 'Gala' fruits in each vertical section was measured with an electronic fruit size measurer (QA Supplies LLC, Norfolk, VA). At the Fruit Research and Extension Center, all 'Fuji' fruit were harvested from each canopy section and all fruit were weighed on an electronic single-lane fruit sizer equipped with a digital load-cell (Durand-Wayland, Inc., LaGange, GA).

Statistical analyses. Descriptive statistics for each cultivar were obtained with SAS's PROC MEANS (Tables 1 and 2). Homogeneity of variances for trees and canopy sections was evaluated with Lavene's test by performing an analysis of variance (ANOVA) on the absolute values of the residuals with PROC GLM (Littell et al., 2002). To compare average fruit weight (FW) or average fruit diameter (FD) for canopy sections, ANOVAs were performed with PROC MIXED and the SIMULATE 
Table 1. Total number of fruit harvested from eight canopy sections of nine 'Gala' trees, mean fruit diameter (FD), and sD for each canopy section for apple trees in Fishertown, PA, in 2016. Cramer-von Mises (CVM) and Anderson-Darlington (AD) tests were used to test the hypothesis that fruit diameters for each canopy section were normally distributed.

\begin{tabular}{lccccc}
\hline & & & & \multicolumn{2}{c}{$P$ values } \\
Variable & Total no. & FD $(\mathrm{mm})$ & SD & CVM & AD \\
\hline Canopy section E & 81 & 69.5 & 0.778 & 0.046 & 0.046 \\
N & 59 & 70.5 & 0.814 & 0.005 & 0.010 \\
NE & 100 & 70.8 & 0.739 & 0.005 & 0.005 \\
NW & 91 & 70.1 & 0.735 & 0.138 & 0.172 \\
S & 79 & 70.9 & 0.768 & 0.038 & 0.031 \\
SE & 103 & 70.2 & 0.736 & 0.107 & 0.099 \\
SW & 99 & 71.0 & 0.731 & 0.014 & 0.014 \\
W & 93 & 70.2 & 0.734 & 0.050 & 0.027 \\
Whole tree & 88.1 & 70.3 & - & - & - \\
\hline
\end{tabular}

Table 2. Total number of fruit harvested from eight canopy sections of 13 'Fuji' trees, along with mean fruit weight (FW) and sD for each canopy section for apple trees in Biglerville, PA, in 2016. Cramervon Mises (CVM) and Anderson-Darlington (AD) tests were used to test the hypothesis that fruit weights for each canopy section were normally distributed.

\begin{tabular}{lclcrc}
\hline & & & & \multicolumn{2}{c}{$P$ values } \\
\cline { 5 - 6 } Variable & Total no. & FW $(\mathrm{g})$ & SD & CVM & AD \\
\hline Canopy section E & 153 & $270 \mathrm{ab}^{2}$ & 3.96 & 0.162 & 0.218 \\
$\mathrm{~N}$ & 127 & $261 \mathrm{~b}$ & 5.01 & 0.099 & 0.104 \\
$\mathrm{NE}$ & 143 & $260 \mathrm{~b}$ & 4.55 & $>0.250$ & $>0.250$ \\
$\mathrm{NW}$ & 140 & $260 \mathrm{~b}$ & 4.47 & $>0.250$ & $>0.250$ \\
$\mathrm{~S}$ & 145 & $272 \mathrm{ab}$ & 4.25 & $>0.250$ & $>0.250$ \\
$\mathrm{SE}$ & 160 & $264 \mathrm{~b}$ & 4.17 & $>0.250$ & $>0.250$ \\
$\mathrm{SW}$ & 173 & $284 \mathrm{a}$ & 3.60 & 0.028 & 0.016 \\
$\mathrm{~W}$ & 135 & $274 \mathrm{ab}$ & 4.18 & 0.117 & 0.089 \\
Whole tree & 90.5 & 268 & & & \\
\hline
\end{tabular}

${ }^{\mathrm{z}} \mathrm{LSmeans}$ within columns followed by common letters do not differ at the $5 \%$ level using the SIMULATE adjustment in PROC MIXED.

adjustment was used to compare the least squares means at the 0.05 experiment-wise error rate (Littell et al., 2006). PROC UNIVARIATE was used to test the hypothesis that FD and FW were normally distributed for each canopy section and $P$ values for the Cramer-von Mises (CVM), and AndersonDarling (AD) tests are presented in Tables 1 and 2. The empirical distribution function (EDF) is a nonparametric estimate of the cumulative distribution function and is used to describe a sample of observations of a given variable, in this case FD or FW. The value of the EDF at a given point is equal to the proportion of observations from the sample that are less than or equal to that point. The nonparametric KolmogorovSmirnov two-sample test, obtained with SAS's PROC NPAR1WAY, was used to test equality of EDFs for all pairs of canopy sections. Since there were eight canopy sections, there were 28 pairwise comparisons. With 28 comparisons and a comparison-wise error rate of 0.05 , the experiment-wise error rate is inflated to 0.76 . To minimize the likelihood of committing a type I error, a comparison-wise error rate of 0.002 was used to provide an experiment-wise error rate $=0.054$.

\section{Results}

'Gala' FD distribution. The total number of fruit harvested from the nine 'Gala' trees was 793 and the mean number of fruit per 'Gala' tree was 88.1 , with a range of 68 to 138 fruit per tree. The mean FD averaged over all nine trees was $70.3 \mathrm{~mm}$ and the mean FD for individual trees ranged from 68.7 to $72.4 \mathrm{~mm}$ (data not shown). The number of fruit per canopy section of individual trees ranged from 2 to 25 , but the average number of fruit per section ranged from 6.6 for the $\mathrm{N}$ section to 11.4 for the SE section (data not shown). SD values were similar for the eight canopy sections and Lavene's test confirmed that variances were homogeneous for trees, canopy sections, and the interaction $(P=0.058$, 0.84 , and 0.45 , respectively). An ANOVA was performed with PROC MIXED (Littell et al., 2006) to test the hypothesis that FD was equal for all eight canopy positions. Average FD ranged from $69.5 \mathrm{~mm}$ for the E canopy section to $71.0 \mathrm{~mm}$ for the SW section, and the differences were not significant $(P=$ 0.778 , Table 1). PROC UNIVARIATE was used to test the hypothesis that FDs were normally distributed for each canopy section. Using a $P$ value of 0.01 , the CVM and AD tests indicated that FD was normally distributed for all canopy sections except the $\mathrm{N}$ and NE sections (Table 1). Histograms describing the percentage of fruit in various categories of FD are shown in Fig. 1. FD peaked at $72.5 \mathrm{~mm}$ for all canopy sections except the $\mathrm{E}$ section, where FD peaked at $68 \mathrm{~mm}$.

Pairwise comparisons of the EDFs indicated that distributions of FD were not different for the eight canopy sections $(P=$ 0.002). EDFs for the NE and NW canopy sections are shown in Fig. 2 because the FDs from those two canopy sections were not normally distributed and they were the two

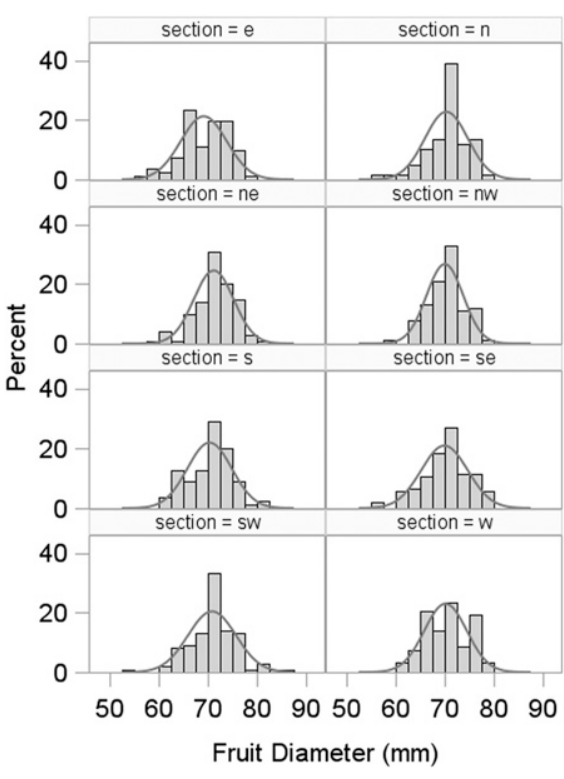

Fig. 1. Distributions of fruit diameters, plus normal curves, for fruit diameter harvested from eight sections of 'Gala' trees in an orchard in Fishertown, PA, in 2016.

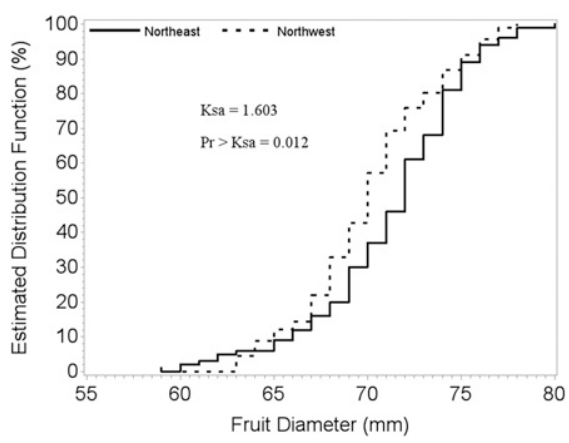

Fig. 2. Estimated cumulative distribution functions for diameter of fruits harvested from the northeast and northwest sections of 'Gala' trees in an orchard in Fishertown, PA, in 2016. The Kolmogorov-Smirnov test statistic (Ksa) of 1.603 is significant at the 0.012 level.

least similar distributions (Fig. 1). The NW section had no fruit with diameters less than $63 \mathrm{~mm}$, whereas $8 \%$ of the fruit from the NE section was less than $63 \mathrm{~mm}$ (Fig. 2). Thirtyseven percent and $57 \%$ of the fruit had diameters of $70 \mathrm{~mm}$ or less for the NE and NW sections, respectively, and $89 \%$ and $91 \%$ of the fruit had diameters of $75 \mathrm{~mm}$ or less for the NE and NW, respectively (Fig. 2). Since the distributions of FD were similar for all eight canopy sections, randomly sampling one section of a tree, which is equivalent to $12.5 \%$ of the tree, should be adequate to provide a reasonable estimate of FD distribution for the entire tree.

'Fuji' $F W$ distribution. The number of 'Fuji' fruit harvested per tree ranged from 71 to 109 . Considering the entire data set of 1176 fruit, weight of individual fruit ranged from 108 to $401 \mathrm{~g}$ (data not shown). Descriptive statistics in Table 2 show that the total number of fruit per canopy section, 
summed over the 13 trees, ranged from 127 to 173 fruit per canopy section. Based on the range of $\mathrm{FW}$ and the $\mathrm{SD}, \mathrm{FW}$ was more variable for the $\mathrm{N}$ than the $\mathrm{E}$ section. Results from Lavene's test indicated that the variances for canopy sections were homogenous, but not for trees. Therefore, a heterogeneous variance component model was fit with PROC MIXED to compare the eight canopy sections. FW was significantly affected by canopy section $(P=0.01)$. Average $\mathrm{FW}$ was greater for the $\mathrm{SW}$ canopy section than for the $\mathrm{N}, \mathrm{NE}, \mathrm{NW}$, and SE canopy sections (Table 2). Based on $P$ values for CVM and AD tests, FW for all canopy sections were normally distributed at the 0.01 level (Table 2, Fig. 3). Although distributions for all sections were about normal, the distribution for the NW section appeared flatter than the other sections. Statistics provided by PROC UNIVARIATE support the formal tests for normality. The FW distribution for the NW canopy section was about symmetrical and slightly skewed to the right (skewness $=+0.25$ ) with relatively light tails (kurtosis $=-0.40$ ). The distribution for the SW section was moderately skewed to the left (skewness $=-0.46$ ) and had moderately heavy tails (kurtosis $=+0.71$ ).

The 28 pairwise comparisons of EDFs for the eight canopy sections showed that the distributions for FW from the SW canopy section were significantly different from the distributions for five of the other seven sections (Table 3). When data from all sections except the SW were combined, the FW distribution for the seven combined sections was significantly different from the distribution for the SW section $(P=0.031$, data not shown). The distributions differed because the SW section had more large fruit. Based on the EDF, $50 \%$ of the fruit from the

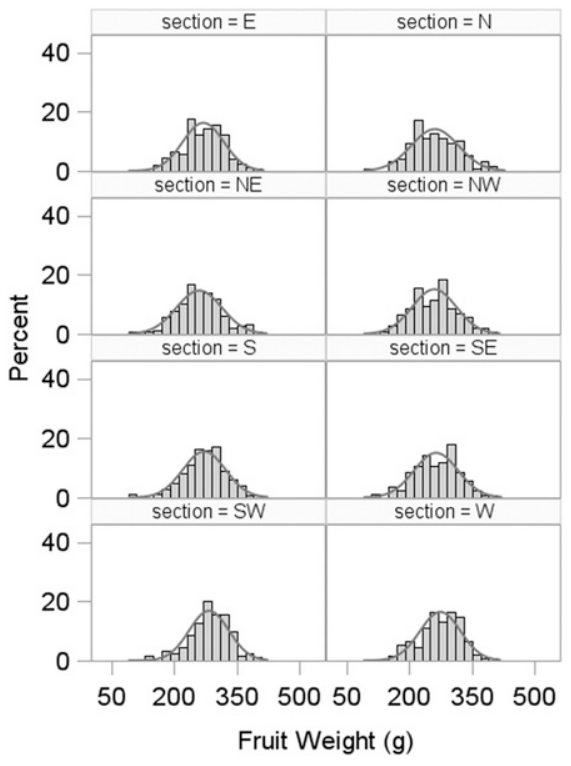

Fig. 3. Distributions of fruit weights, plus normal curves, for fruit harvested from eight sections of 'Fuji' trees in an orchard in Biglerville, PA, in 2016 .
SW section was equal to or smaller than $285 \mathrm{~g}$, whereas for the remaining seven sections $50 \%$ of the fruit was equal to or smaller than only 266 g (Fig. 4). Since FW distributions for the eight canopy sections were not homogeneous, it is unlikely that the distribution of fruit for an entire tree can be adequately estimated by sampling a single canopy section ( $12.5 \%$ of the canopy). Therefore, two or more sections were combined and compared with other combinations of sections. When fruit from the SW and S sections were combined, the fruit were larger than fruit from the combination of remaining sections, but the two distributions were not significantly different $(P=0.326)$. Six other combinations of two sections were compared with the combination of the remaining six sections and in every case the two distributions were not significantly different at the $5 \%$ level. When fruit from the four cardinal $(\mathrm{N}, \mathrm{E}, \mathrm{S}, \mathrm{W})$ sections of the canopy were combined and compared with the fruit combined from the four ordinal (SE, SW, NW, $\mathrm{NE}$ ) sections, the distributions were nearly identical (Fig. 4). Combining fruit from four sections to compare the south vs. north and east vs. west sides of the tree was better than sampling fruit from just two sections (data not shown) but combining the cardinal or ordinal sections provided the best estimate of fruit size distribution. A combined fruit sample from any two sections of the canopy ( $25 \%$ of the canopy) should provide a reasonable estimate of the fruit size distribution for an entire tree, but if an extremely accurate estimate is required, then the sample should be obtained by harvesting all fruit from either the four ordinal or cardinal sections.

Estimating 'Gala' average FD. Estimates for FD for each canopy section were plotted against the true mean FD calculated from all fruit on each tree and plots show the line of equality on which all points would lie if the estimates for a section gave exactly the same value as the true value (Fig. 5). FD estimates from the NW and W canopy sections were closer to the true values than estimates from the $\mathrm{N}$ and $\mathrm{S}$ sections. These plots are more informative than performing regression of estimated FD against the true FD, but a plot of the differences against the true values is

Table 3. Matrix of $P$ values for pairwise comparisons of distributions of fruit weight for eight canopy sections of 13 'Fuji' trees in Biglerville, PA, in 2016. $P$ values were obtained with the Kolmogorov-Smirnov two-sample test.

\begin{tabular}{lccccccc}
\hline Canopy section & NE & E & SE & S & SW & W & NW \\
\hline N & 0.320 & 0.036 & 0.56 & 0.014 & 0.001 & 0.008 & 0.771 \\
NE & & 0.303 & 0.438 & 0.121 & 0.001 & 0.014 & 0.790 \\
E & & & 0.329 & 0.519 & 0.005 & 0.629 & 0.033 \\
SE & & & & 0.154 & 0.001 & 0.0046 & 0.319 \\
S & & & & 0.061 & 0.944 & 0.049 \\
SW & & & & & 0.062 & 0.001 \\
W & & & & & & 0.012 \\
\hline
\end{tabular}
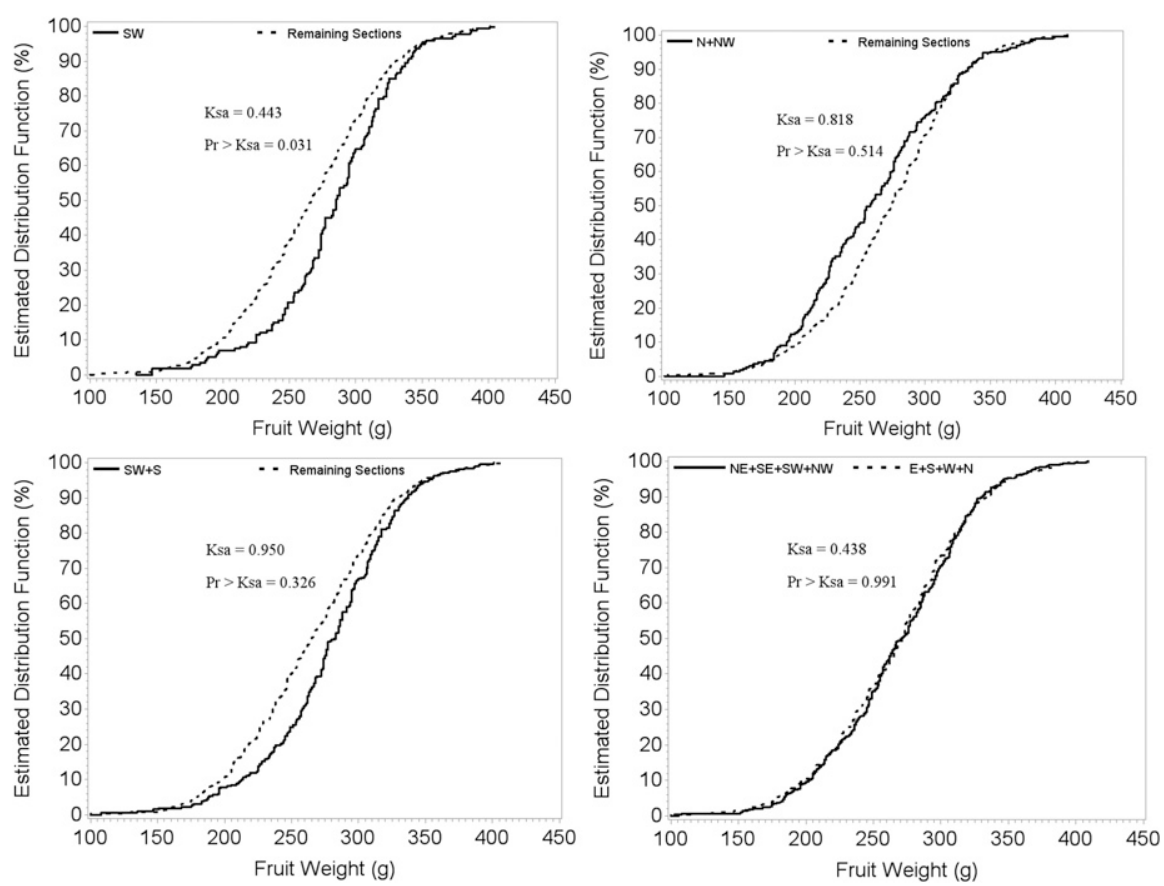

Fig. 4. Estimated cumulative distribution functions (EDF) for fruit weights of fruits harvested from different sections of 'Fuji' trees in an orchard in Biglerville, PA, in 2016. The EDFs for various combinations of canopy sections were compared with Kolmogorov-Smirnov two-sample test and the test statistic (Ksa) and $P$ value associated with the test are presented in each figure. 
often even more informative (Bland and Altman, 1986). Lack of agreement between the estimated values of $\mathrm{FW}$ and the true values can be evaluated by calculating the bias, estimated by the mean of the differences (d) and the SD of the differences. In Fig. 6 the center horizontal line represents the mean of the differences (FW estimated for a canopy section - the mean FW for the whole tree). If the differences are normally distributed, 95\% of the differences will lie between $d \pm 2$ SD and these are called the limits of agreement, represented by the upper and lower horizontal lines in Fig. 6. Provided that differences within the limits of agreement are acceptable, average FD values from a single canopy section can be used to estimate the true FD values for the tree. These differences typically follow a normal distribution because much variation between trees was removed and the measurement error remains (Bland and Altman, 1986). The estimates did not appear biased because the plots did not exhibit any patterns. The differences were smallest for the NW, intermediate for the E, and largest for the S canopy sections (Fig. 6). Estimates from the $\mathrm{S}$ section may be $5.6 \mathrm{~mm}$ above and $4.0 \mathrm{~mm}$ below the true value; estimates from the $\mathrm{E}$ section may be $3.8 \mathrm{~mm}$ above or $4.4 \mathrm{~mm}$ below the true value; and estimates from the NW section may be $2.4 \mathrm{~mm}$ above and $2.9 \mathrm{~mm}$ below the true value.

According to Bland and Altman (1986), the limits of agreement are only estimates of the values that apply to the entire population and a second sample would give different limits. Therefore, we used SE and confidence intervals (CIs) to examine the precision of the estimates. The $95 \% \mathrm{CI}$ for the bias is $d \pm \mathrm{t}_{0.05}$ $(\mathrm{SD} / \sqrt{\mathrm{n}})$, which is narrower than the limits of agreement. Differences from the true mean, along with $95 \%$ CIs, obtained with PROC MEANS were plotted for FD estimated from each 'Gala' canopy section as well as estimates from combinations of two, four, and seven sections (Fig. 7). As the number of sections, representing larger proportions of the canopy, increased, the difference was closer to zero and the CIs became narrower. 'Gala' FD estimates obtained from one canopy section were generally 0.5 to $1.0 \mathrm{~mm}$ from the true mean. Estimates obtained with two sections $(25 \%$ of the canopy), varied from 0.1 to $0.8 \mathrm{~mm}$ from the true mean. Estimates obtained from four sections $(50 \%$ of the canopy) were within 0.0 to $0.5 \mathrm{~mm}$ from the true mean and estimates obtained from seven sections ( $87.5 \%$ of the canopy) were within 0.1 to $0.3 \mathrm{~mm}$ from the true mean (Fig. 7). Based on the 95\% CIs, FD estimates obtained from one, two, and four canopy sections may be within $3.0 \mathrm{~mm}, 2.2 \mathrm{~mm}$, and $1.0 \mathrm{~mm}$ of the true mean, respectively. Since the overall average FD was $70.3 \mathrm{~mm}$, obtaining average FD estimates from one, two, and four canopy sections would be within $5 \%, 3 \%$, and $1.5 \%$ of the true mean FD, respectively.

Estimating 'Fuji' $F W$. Values of average FW estimated from single canopy sections

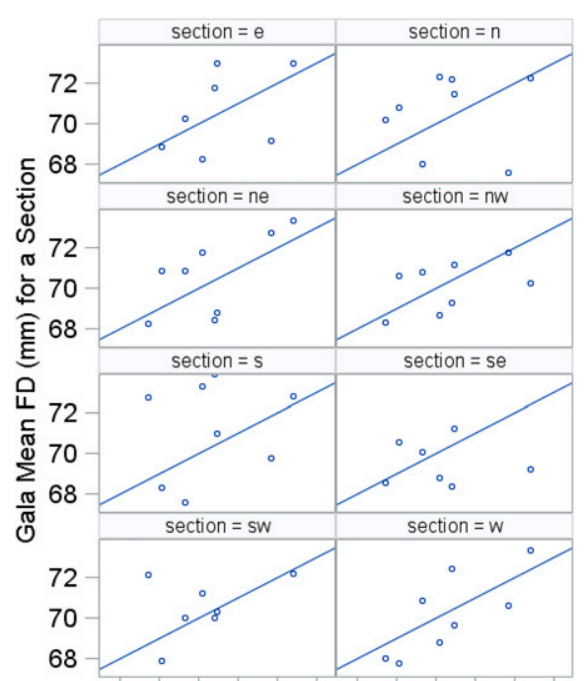

686970717273686970717273

True Mean FD $(\mathrm{mm})$

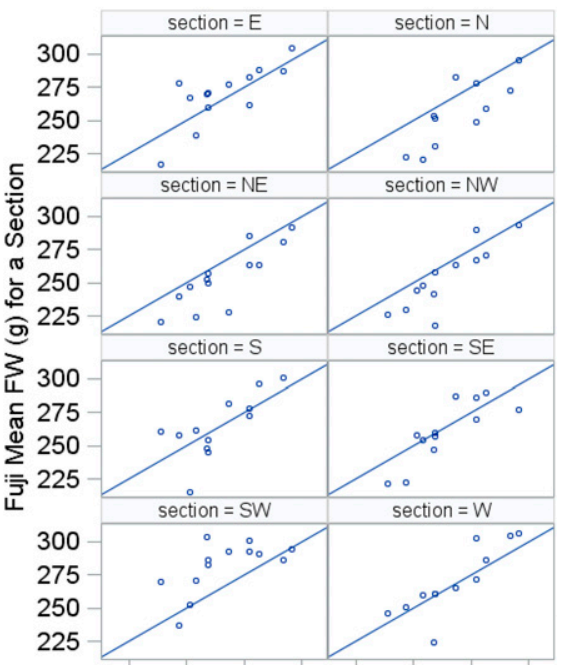

225250275300225250275300

Fuji True Mean FW (g)
Fig. 5. Scatter plots of mean fruit diameter and mean fruit weight (FW) estimated from the fruit harvested from a section of the canopy vs. the true mean fruit diameter calculated from all the fruit on a tree. The $45^{\circ}$ line is the line of equality on which all points would lie if the estimated value was equal to the true value.
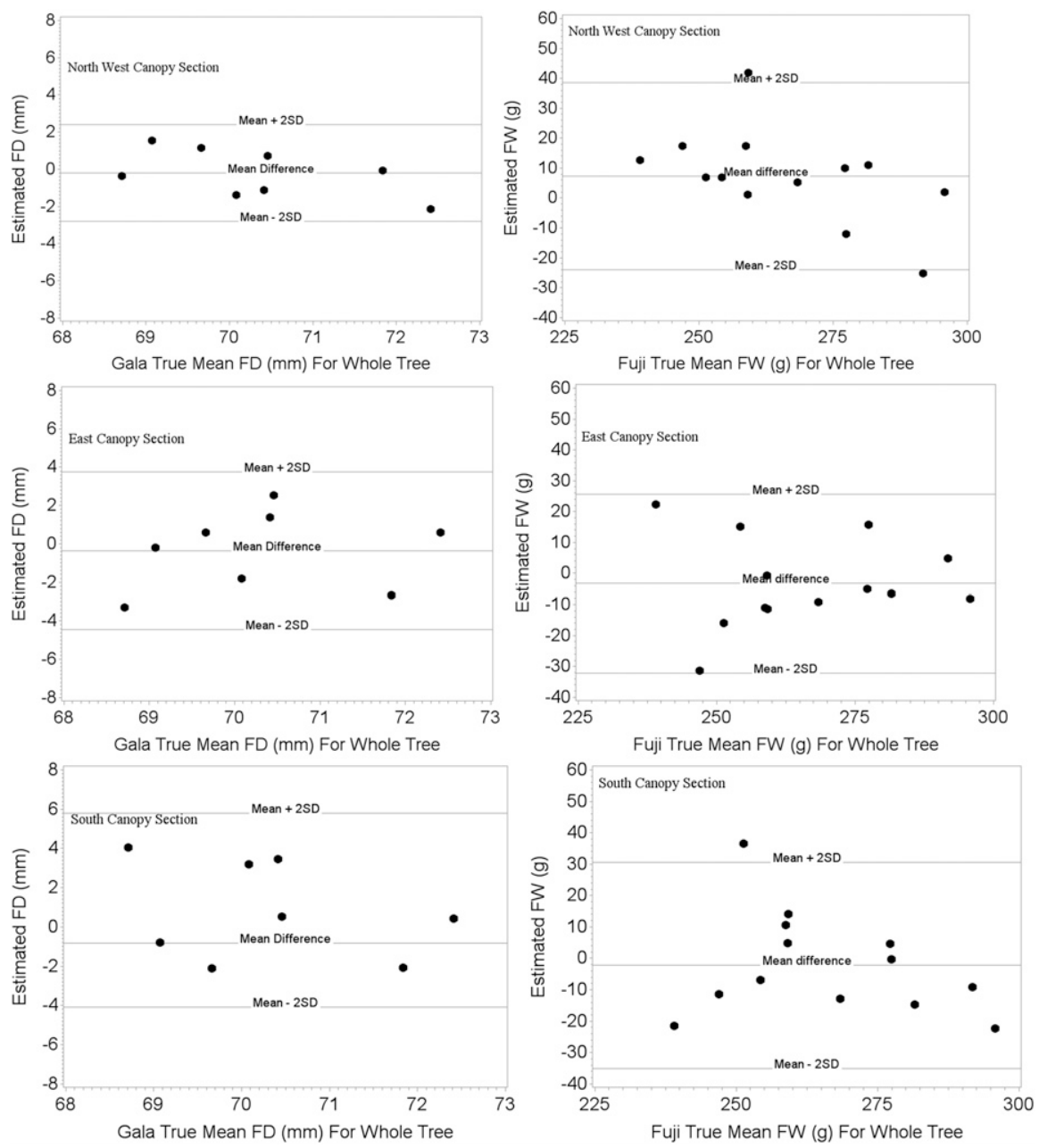

Fig. 6. The difference between mean fruit diameter (FD) and mean fruit weight (FW) estimated from fruit harvested from three canopy sections vs. the true mean FD or FW for individual whole trees. If the differences are normally distributed, $95 \%$ of the differences will lie between the limits of agreement (upper and lower lines). 
for 'Fuji' fell closer to the line of equality than did FD estimates for 'Gala' (Fig. 5). FW estimated from the N, NE, and NW canopy sections tended to be biased because most points fell below the line of equality, whereas the opposite was true for the E, S, and SW sections. Although the limits of agreement were smallest for the NW section of 'Gala' trees, the limits of agreement were largest for the NW section of 'Fuji' trees (Fig. 6). FW estimates from the NW section may be $37.0 \mathrm{~g}$ above and $24.0 \mathrm{~g}$ below the true value; estimates from the E section may be $25.0 \mathrm{~g}$ above or $33.0 \mathrm{~g}$ below the true value; and estimates from the SW section may be $30.0 \mathrm{~g}$ above and $36.0 \mathrm{~g}$ below the true value. Similar to results for 'Gala', as the proportion of the total fruit on trees used to estimate FW increased, mean differences approached zero and the CIs became narrower for 'Fuji' (Fig. 7). FW estimated from the SW canopy section differed most from the true mean. Based on the $95 \%$ CIs, average FW estimated from just the SW section may be as little as $7.0 \mathrm{~g}$ below the true value and or as much as $22.0 \mathrm{~g}$ below the true value. Average FW estimated from the E section was most like the true value and was about $4.0 \mathrm{~g}$ below the true value, but estimates may be $12.0 \mathrm{~g}$ below and $5.0 \mathrm{~g}$ above the true value. When fruit from two sections were used to estimate average FW, the estimate was always within $11.0 \mathrm{~g}$ above or below the true value. Estimating FW from fruit harvested from four or more sections of the tree usually gave estimates within $7.0 \mathrm{~g}$ of the true value. The average FW for the 13 'Fuji' trees was $268 \mathrm{~g}$ (Table 4). Therefore, average FW estimated from one section may provide estimates within $8 \%$ of the true mean, estimates based on 2 canopy sections may provide estimates within $7 \%$ of the true value, and estimates based on four canopy sections may provide estimates within $3 \%$ of the true value.

\section{Discussion}

Understanding within-tree variation is important to reliably estimate the average fruit size or fruit size distribution for a tree. De Silva et al. (2000) identified systematic trends in FW within the canopy of relatively large 4- to 5m-tall slender-pyramid 'Gala' trees. On lower limbs FW increased from the base outwards, but the opposite was true for the upper limbs, and at the base of the limbs FW increased from the lower limbs to the upper limbs. They suggested that sampling along a limb will result in more efficient estimates of mean FW compared with random or systematic sampling. Previous attempts to estimate fruit size or fruit size distribution were often based on samples of fruit rather than for the entire population of fruit on the tree. Zhang et al. (1995) sampled 20 'Gala' fruit from three canopy positions of five trees in 15 orchards in two seasons, and average FW was positively correlated with the SD. Like our study, they reported that FW for the 30 combinations of years and orchards was normally distributed, but their SD
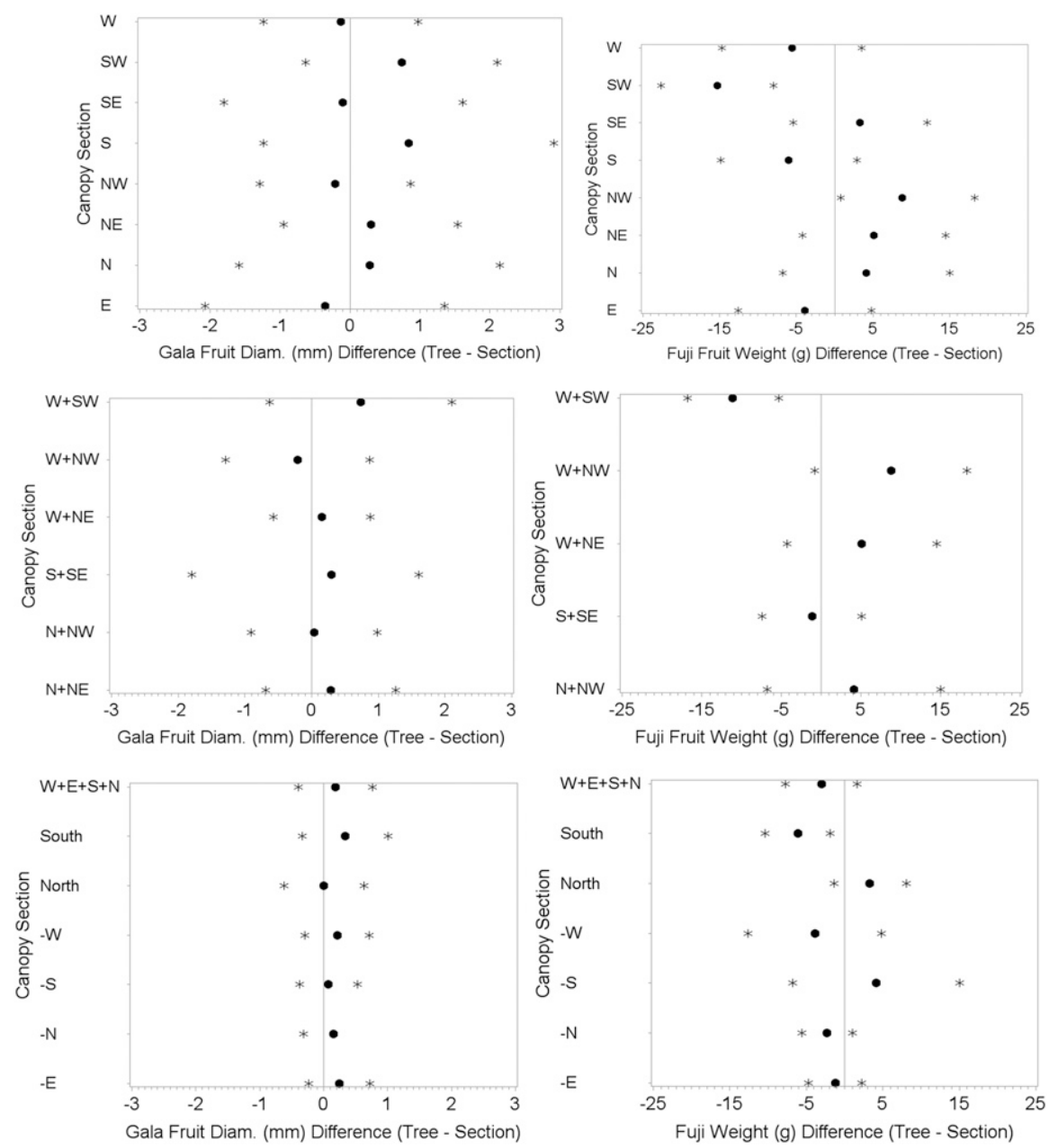

Fig. 7. Average difference in 'Gala' fruit diameter ( $\mathrm{mm}$ ) or 'Fuji' fruit weight (g) between whole trees and various section of the canopy. Dots represent the average difference and asterisks represent the upper and lower $95 \%$ confidence intervals. Top figure shows differences for single canopy sections; middle figure shows differences for combinations of two sections; and the lower figure shows differences for combinations of four sections or seven sections. Negative signs before the compass direction indicates a combination of all canopy sections except for the designated section.

Table 4. Mean difference in fruit diameter or fruit weight estimated from the entire tree versus a canopy section. $95 \%$ of the differences will fall between the lower and upper limits.

\begin{tabular}{|c|c|c|c|c|c|c|}
\hline \multirow{2}{*}{$\begin{array}{l}\text { Canopy } \\
\text { section }\end{array}$} & \multirow{2}{*}{$\begin{array}{l}\text { Mean fruit diam. } \\
\text { difference }(\mathrm{mm})\end{array}$} & \multicolumn{2}{|c|}{$\begin{array}{c}\text { Gala } 95 \% \text { limits } \\
\text { of agreement }(\mathrm{mm})\end{array}$} & \multirow{2}{*}{$\begin{array}{l}\text { Mean fruit wt } \\
\text { difference }(g)\end{array}$} & \multicolumn{2}{|c|}{$\begin{array}{l}\text { Fuji 95\% limits } \\
\text { of agreement }(\mathrm{g})\end{array}$} \\
\hline & & Lower & Upper & & Lower & Upper \\
\hline $\mathrm{E}$ & $-0.357^{\mathrm{z}}$ & -4.46 & 3.74 & -3.23 & -35.9 & 29.5 \\
\hline $\mathrm{N}$ & 0.280 & -4.12 & 4.68 & 16.50 & -53.9 & 86.9 \\
\hline NE & 0.296 & -2.70 & 3.29 & 12.03 & -43.6 & 67.6 \\
\hline $\mathrm{E}$ & 0.838 & -4.10 & 5.78 & 7.23 & -63.2 & 77.6 \\
\hline SE & -0.210 & 2.39 & -2.81 & -2.28 & -35.2 & 63.5 \\
\hline S & -0.096 & -4.18 & 3.98 & 0.64 & -67.8 & 69.0 \\
\hline SW & 0.737 & -2.53 & 4.01 & -15.24 & -56.0 & 25.6 \\
\hline W & -0.133 & -1.45 & 2.49 & -1.42 & -66.6 & 63.8 \\
\hline
\end{tabular}

${ }^{\mathrm{z}}$ The estimate of fruit diameter from the east section of 'Gala' trees may be $4.46 \mathrm{~mm}$ below or $3.74 \mathrm{~mm}$ above the true fruit diameter obtained from the entire tree.

(20-30 g) were nearly 6 times greater than for 'Fuji' in our study (3.6-5.0 g). Lower variation in our study was expected because our trees were small, and effects of within-canopy shading and other factors were probably minimal. Previous reports did not provide details concerning fruit thinning, and the follow-up hand thinning in this study likely enhanced fruit size uniformity. Using the mean and $\mathrm{CV}$,
Zhang et al. (1995) estimated the percentage of fruit that would fall into a given fruit count size. De Silva et al. (1997) recorded the diameters of a sample of apples at 14-day intervals throughout the season and attempted to predict fruit size distribution at harvest. Fruit size distributions of their sampled fruit changed during the season and the predictions were not very accurate. 
In recent years, the apple industry has generally transitioned to relatively small trees less than $4 \mathrm{~m}$ tall and with narrow canopies less than $2.0 \mathrm{~m}$ in diameter at the widest point. Light distribution throughout the canopy of these modern trees is likely more uniform, leading to less systematic variation in fruit size and quality. Harvesting a relatively large proportion of the fruit on small trees is much easier than with large trees. Dorsey and McMunn (1938) were probably the first to evaluate sampling methods for estimating apple fruit size. They found that sampling 100 fruit per tree, harvesting all fruit on one limb per tree, or harvesting all the fruit from a vertical section of the tree did not provide accurate estimates of average FW. These were large trees, and they found that harvesting about $25 \%$ of the crop $(91.0 \mathrm{~kg} /$ tree $)$ provided estimated mean FWs within about $10 \%$ of the true mean. Marini (2001) used relatively small central leader 'Redchief Delicious'/M.26 trees with about 400 fruit per tree and found that a random sample of 20 fruit per tree $(5 \%$ of the crop) was nearly as accurate as a 60 -fruit (17\% of the crop) sample obtained by harvesting all fruit on three limbs. Trees used for the present study were much smaller, with an average of only 88 and 147 fruit per tree for 'Gala' and 'Fuji', respectively. As previously reported, the estimated FW more closely approximated the true value as the proportion of fruit sampled from trees increased.

To our knowledge, this is the first report in which fruit size distributions from different canopy sections were compared. The fact that the fruit size distributions were similar for different canopy sections supports the concept that canopy position affects fruit size to a much less extent in small trees than in larger trees, where light distribution is less uniform. Our results indicate that sampling all fruit from about $25 \%$ of the canopy will provide estimates of average $\mathrm{FW}$ within $7 \%$ of the true mean and the distribution of fruit size will be similar to the distribution for the whole tree. If very accurate estimates are needed, then harvesting all fruit from the ordinate or coordinate sections $(50 \%)$ of the canopy is suggested.

Methods have been published to predict apple fruit size at harvest from early-season measurements (Batjer et al., 1957; Forshey,
1971; Marini et al., 2019). The next step in predicting fruit size distribution at harvest from early-season fruit measurements is to measure FD or FW of all the fruit from at least $25 \%$ of the canopy $60 \mathrm{~d}$ after bloom. Using previously published models to predict fruit size at harvest from early-season measurements (Marini et al., 2019), the predicted distributions can be compared with the true distributions using all the fruit on the whole tree. Agricultural engineers are developing technologies to nondestructively count and measure fruit in orchards and our data indicate that recording data all fruit on one side of a small tree can provide accurate estimates of fruit size and fruit size distribution.

\section{Literature Cited}

Barden, J.A. and R.P. Marini. 1998. Growth and cropping of young apple trees as affected by heading and support of the central leader. HortScience 33:39-41.

Batjer, L.P., H.D. Billingsley, M.N. Westwood, and B.L. Rogers. 1957. Predicting harvest size of apples at different times during the growing season. Proc. Amer. Soc. Hort. Sci. 70:46-57.

Bland, J.M. and D.G. Altman. 1986. Statistical methods for assessing agreement between two methods of clinical measurement. Lancet $1: 307-310$.

Clarke, G.M. 1990. The relation between weight and diameter in apples. J. Hort. Sci. 65:385-393.

De Silva, H.N., A.J. Hall, W.M. Cashmore, and D.S. Tustin. 2000. Variation of fruit size and growth within an apple tree and its influence on sampling methods for estimating the parameters of midseason size distribution. Ann. Bot. 86:493-501.

De Silva, H.N., C.D. Lai, and R.D. Ball. 1997. Fitting SB distributions to fruit sizes with implications for prediction methods. J. Agr. Soil. Environ. Stat. 2:333-346.

Dorsey, M.J. and R.L. McMunn. 1938. A comparison of different methods of taking samples of apples in experimental plots. Proc. Amer. Soc. Hort. Sci. 36:619-626.

Dozier, W.A., Jr., W.A. Griffey, and H.F. Burgess. 1980. Effect of growth regulators on the development of 'Delicious' apples. HortScience 15:743-744.

Fallahi, E., B. Fallahi, B. Shafii, D. Neilson, and G.H. Neilson. 2011. The impact of long-term evapotranspiration-based water scheduling in various irrigation regimes on tree growth, yield, and fruit quality at harvest in 'Fuji' apple. J. Amer. Pomol. Soc. 65:42-53.
Forshey, C.G. 1971. Predicting harvest size of McIntosh apple. N.Y. Food and Life Sci. Bull. No. 9.

Greene, D.W. 1986. Effect of paclobutrazol and analogs on growth, yield, fruit quality, and storage potential of 'Delicious' apples. J. Amer. Soc. Hort. Sci. 111:328-332.

Hampson, C.R., H.A. Quamme, and R.T. Brownlee. 1997. Performance of dwarfing rootstocks in five trials in British Columbia, Canada. Fruit Var. J. 51:183-191.

Littell, R.C., W.W. Stroup, and R.J. Freund. 2002. SAS ${ }^{\circledR}$ for linear models. 4 th ed. SAS Institute, Inc., Cary, NC.

Littell, R.C., W.W. Stroup, R.D. Wolfinger, and O. Schabenberger. 2006. SAS ${ }^{\circledR}$ for mixed models. 2nd ed. SAS Institute, Inc., Cary, NC.

Marini, R.P. 2001. Estimating mean fruit weight and mean fruit value for apple trees: Comparison of two sampling methods with the true mean. J. Amer. Soc. Hort. Sci. 126:503-510.

Marini, R.P., J.A. Barden, and D. Sowers. 1993. Growth and fruiting responses of 'Redchief Delicious' apple trees to heading cuts and scaffold limb removal. J. Amer. Soc. Hort. Sci. 118:446-449.

Marini, R.P., J.R. Schupp, T.A. Baugher, and R. Crassweller. 2019. Relationships between fruit weight and diameter at 60 days after bloom and at harvest for three apple cultivars. HortScience 54:86-91.

McClure, K.A. and J.A. Cline. 2015. Mechanical blossom thinning of apples and influence on yield, fruit quality and spur leaf area. Can. J. Plant Sci. 97:601-609.

Miller, S.S. 1982. Regrowth, flowering, and fruit quality of 'Delicious' apple trees as influenced by summer pruning. J. Amer. Soc. Hort. Sci. 107:975-978.

Schupp, J.R., H.E. Winzeler, T.M. Kon, R.P. Marini, T.A. Baugher, L.F. Kime, and M.A. Schupp. 2017. A method for quantifying whole-tree pruning severity in mature tall spindle apple plantings. HortScience 52:1233-1240.

Stefanelli, D., R.J. Zoppolo, and R.L. Perry. 2009. Organic orchard floor management systems for apple effect on rootstock performance in the Midwestern United States. HortScience 44: 263-267.

Visser, C.J. and J.A. Pieterse. 1977. A proposed model for determining apple size distribution of a crop. Deciduous Fruit Grower 27:50-53.

Webb, R.A., J.V. Purves, and M.G. Beech. 1980. Size factors in apple fruit. Scientia Hort. 13: 205-212.

Zhang, J., G.F. Thiele, and R.N. Rowe. 1995. Gala apple fruit size distribution. N. Z. J. Crop Hort. Sci. 23:85-88. 